\title{
Marketing Decision Making by Applying the Expert System
}

\author{
Radovan Pejanović \\ University of Novi Sad, Faculty of Agriculture, Serbia \\ Otilija Sedlak \\ University of Novi Sad, Faculty of Economics, Serbia \\ Zoran Ćirić \\ University of Novi Sad, Faculty of Economics, Serbia \\ Leposava Grubić-Nešić \\ University of Novi Sad, Faculty of Technical Sciences, Serbia \\ Slavica Mitrović \\ University of Novi Sad, Faculty of Technical Sciences, Serbia \\ Jelica Eremić-Đođić \\ Elektroprivreda Srbije, Serbia
}

\section{Abstract}

The main goal of this paper is to develop an expert system based on fuzzy set theory that will provide more successful and efficient decision making in the area of marketing, in relation with dilemma "to produce or to purchase". Namely, authors will try to develop a model that will be suitable for making marketing decisions in production systems. Methodology in the paper obtained analysis of the theory of marketing, the development of the specific model for decision making, so as the application of developed model on one case from production system. Methodology which allows to model indeterminacy is fuzzy sets theory which is particularly well designed for dealing with non-probabilistic uncertainties. Authors will develop a model for decision making, based on successful integration of marketing and fuzzy theories. They will implement the model in decision making problem related to the debate "to produce or to purchase" on one real decision problem in production system. The main goal of this paper is to make changes in the work of decision makers in marketing sector. Authors pointed the advantages of the model with quality management, but also some limitations and possibilities for the future researches.

Keywords: fuzzy logic, decision support systems, ICT, uncertainty JEL classification: C63

\section{Introduction}

The marketing management comprises all those activities associated with the transformation and flow of goods and services, including their attendant information flows, from the sources of materials to end users. Management refers to integration of all these activities, both internal and external to the firm.

The main goal of this paper was to make changes in the work of decision makers in marketing sector. The authors expanded and changed the decision making system, by developing and installing a new model for decision making. In this paper we had a new model with several inputs and one output. Input elements on the lower level become fuzzy. The outcome of the model is a decision, which is 
influenced by a considerable number of factors and the soundness of assumptions. This model could simulate sustainable functioning of the production process.

Marketing decision makers include marketing managers, analysts, and also formal or informal authorities featuring in the process of choosing marketing alternatives. They feature both on the supply and demand side, given that a social and managerial process by which individuals and groups obtain what they need and want through creating and exchanging products and values with others (Kosko, 1992). High uncertainty and risk levels result from disruptive innovations and great unexpected shocks (Kotler, 2000). Decision makers often prefer to employ oral presentation rather than numerical value. In such conditions the best solution is to make decisions on the basis of multiple conditions and goals to achieve a relatively desirable level of achievement (Kang al., 2011). These issues have caused the nature of decision making to be full of complexities and ambiguities in the most minor to most major cases. Consequently, most decisions are made in a fuzzy environment. Therefore, considering that the fuzzy logic method is proposed for decision making in uncertain and ambiguous situations, using this method can reduce ambiguities and increase the effectiveness of decisions made (Ertugrul al., 2009). Vorhies and Morgan in their paper recognized that the key mechanism for identifying, building, and enhancing of production process capabilities to deliver sustainable competitive advantage, through marketing decision models (Vorhies al., 2005).

The paper organization follows these steps: literature review, about of marketing decision problem and the importance of marketing management sustainability. It is also about hesitant fuzzy sets. The third and fourth part presents the problem and the model. The authors posed the model and performed an in-depth analysis and construction of constraints' coefficients. Results are presented and differences between results of similar studies are pointed out. The last part contains conclusions with advantages and limitations of the given model, the guidelines and possibilities for the future research.

\section{Problem Formulation}

Making marketing decisions is aimed in two basic directions, i.e. towards solving problems on the one hand and using the benefits of business opportunities on the other. At any rate, marketing decision making enables a transition from the current state into a new, i.e. desired state, which marketing decision makers deem to be more favorable for the company.

Decision is made under conditions of risk, when the only knowledge available regarding the state of outcomes is their probability distribution. The outcome of these decisions is influenced by a considerable number of factors and the soundness of assumptions. Traditionally, cost had been viewed as the main consideration in sourcing decision (Maltz al., 2012). Also, one more factor which is important in the process of sourcing decision making is the level of technology development. For example, on the basis of 1990-2002 panel data set on Spanish companies and an exogenous proxy for technological change it have been provided thee causal evidence that technological change increases the likelihood of outsourcing (Bartel al., 2012).

\section{Methodology}

It is due to the importance of additional criteria that a prototype of the expert system was developed (including software solutions). As the economic model in Figure 1 shows, the number of attributes taken into account is far greater compared to the classical decision making method. 
The decision maker communicates with the expert system by choosing the domains of values for the attribute of the decision making leaf nodes. Using the builtin logarithm, the expert system proposes a solution with explanation based on these data.

Managing and modeling of uncertainty by different forms of information, used by experts to provide their preferences, can be done in various ways, including utility vectors, fuzzy preference relations, linguistic variables, interval values, multiplicative preference relations, hesitant fuzzy sets.

A solution to the given problem by applying fuzzy set theory, the economic model (Figure 1) can be supplemented with an oriented graph.

Figure 1

Decision tree for problem solving: "Produce or purchase"

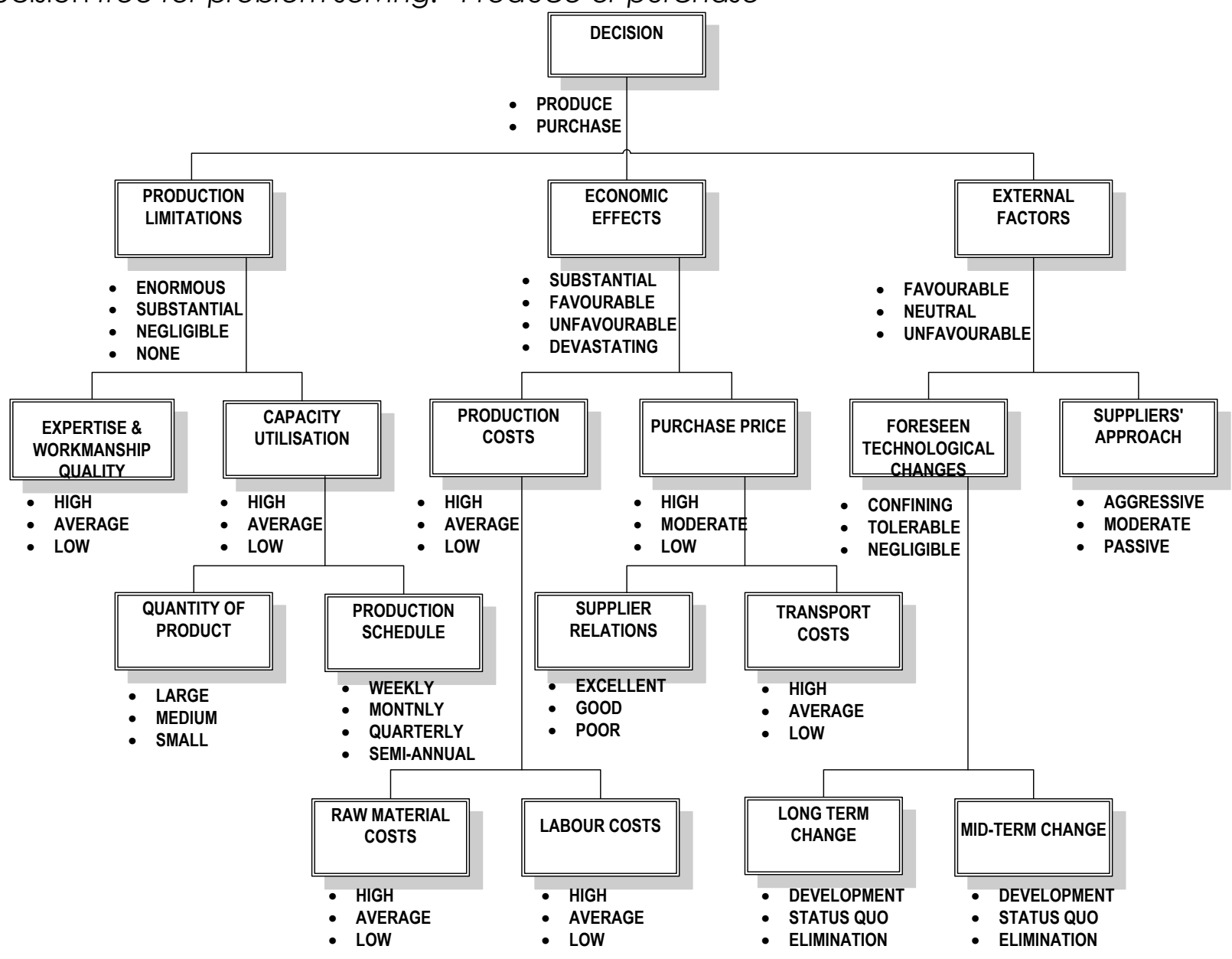

Source: Author's illustration

The Fuzzy Approximation Theorem says more than that. Theoretically, all equations can be translated into rule patches. Fuzzy systems approximate systems in physics, communication, physiology, etc. Fuzzy systems can be applied wherever the brain is used (Ciric al., 2015).

The Model

Let us observe a company ' $Y$ ' consisting of $S$ sectors, which are producing a different type of products. Characteristics (arguments, input variables) include expertise and developing workmanship quality, quality of product, production schedule, raw 
material costs, labor costs, supplier relations, transport costs, long term change, midterm change, supplier approach.

These are not arguments in the classical mathematical sense. The input variables (arguments) are linguistic variables ("high raw material costs", "medium quantity of product", "aggressive suppliers' approach", "status quo in the forthcoming 3-5 years, but development over the subsequent ten plus years", etc). The same applies to output variables (functions), representing input functions for complex functions up to the last level, such as production costs, purchase price, foreseen technological change, production limitations etc. Such nature of input and output variables, i.e. value domains that cannot be accurately quantified, make the fuzzy set theory extremely convenient for problem solving in marketing decision making.

This is how resolving the above described problem was approached. Input and output variables were defined as different fuzzy sets, both continuous and discontinuous. Defining fuzzy sets intrinsically implies that the appropriate degree of belonging is ascribed to all possible values (Sedlak al., 2013).

\section{Results}

The approximate reasoning algorithm for making the business decision whether to produce or purchase consists of three basic steps. Each basic step is divided into several interconnected steps. Each of these substeps, or steps, contains a logical inference rule defined by experts. As specified numeric values directly entered at the given moment of making the "purchase or produce" decision, the input data are as follows: expertise, quantity of product, production schedule, raw material costs, labor costs, supplier relations, transport costs, and long- and mid-term changes. Fuzzy sets are already prepared at all levels. Direct entry of the above listed first- and second-level data activated the above defined algorithm. Production costs are defuzzified (Figure 2 ) by determining the centre of gravity using the known formula. Thus obtained numerical data is the input value for step 2. 
Figure 2

Decision making with defuzzification

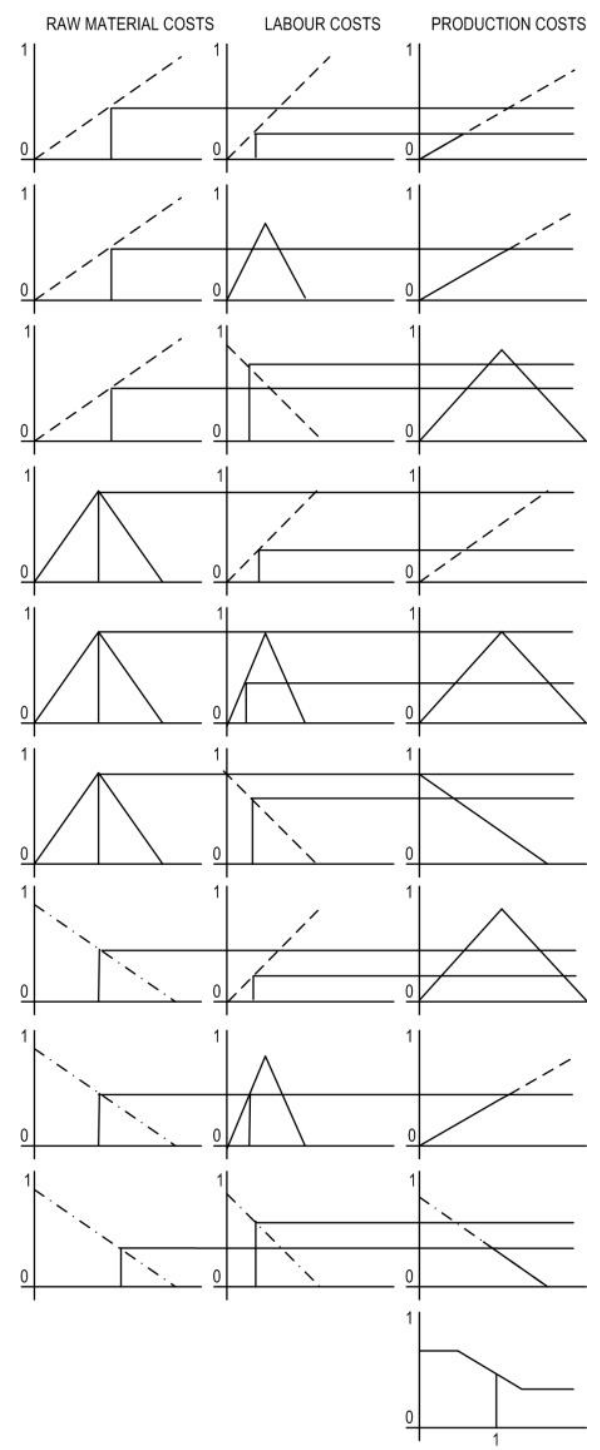

Source: Author's illustration

\section{Conclusion}

In this article the accent was on presenting a new method in decision making for business decision "purchase or produce". The problem has all the characteristics of uncertainty. Serious problems, and the limitations, are determining of input variables and forecasting all possible circumstances, which is only possible based on subjective estimate. An estimate with a degree of accuracy is much easier to obtain for a range of data than for an individual value. Certain characteristics of input variables cannot be measured precisely, and an expert's opinion is needed.

Fuzzy sets can be introduced into the existing decision making models in several ways. As an economic institution, a company bases its existence on the environment, both from the aspect of providing input and from the aspect of achieving and valorizing input. Miscellaneous knowledge and experience, and also decision making in the areas of investment, market operations, financial function, production function or research and development, can be considered more fully and exactly applying fuzzy sets. The fuzzy set theory provides a solution to this. 
Individual steps of the algorithm are based on fuzzy logic rules. The algorithm was verified on multiple numeric examples, and development of an appropriate software product is in progress. The essential feature of this algorithm is that there is no possibility of "setting up" a desirable decision by tailoring input data.

Miscellaneous knowledge and experience, and also decision making in the areas of investment, market operations, financial function, production function or research and development, can be considered more fully and exactly applying hesitant fuzzy sets and these will be fully investigated in our future work.

\section{References}

1. Bartel, A. P., Lach, S., Sicherman, N. (2012), "Technological change and the makeor-buy decision", Journal of Law, Economics, and Organization, pp. 1-28.

2. Ćirić, Z., Stojić, D., Sedlak, O. (2015), "Multicriteria HR allocation based on hesitant fuzzy sets and possibilistic programming", Acta Polytechnica Hungarica, Óbuda University, Hungarian Academy of Engineering and IEEE Hungary Section, Vol. 12 No. 3, pp. 185-197.

3. Coase, R., (1937), "The Nature of the Firm", Economica, Vol. 4 No. 16, pp. 386-405.

4. Ertugrul, I, \& Karakasoglu, N. (2009), "Performance evaluation of Turkish cement firms with fuzzy analytic hierarchy process and TOPSIS methods", Expert Systems with Applications, Vol. 36 No. 1, pp. 702-715.

5. Kang, H., Hung, M., Pearn, W. L., Lee, A.H. I., M. (2011), "An Integrated Multi-Criteria Decision Making Model for Evaluating Wind Farm Performance", Energies, Vol. 4, No. 11 , pp. 2002-2026.

6. Kosko, B. (1992), "Neural Networks and Fuzzy Systems", Englewood Cliffs: Prentice Hall, New Jersey.

7. Kotler, P. (2000), "Marketing management: The millennium edition", Upper Saddle River, NJ: Prentice-Hall.

8. Maltz, A., Carter, J. R., \& Maltz, E. (2011), "How managers make sourcing decisions about low cost regions: Insights from perceptual mapping", Industrial Marketing Management, Vol 40, No. 5, pp. 796-804.

9. Sedlak, O., Ćirić, Z., Ćirić, I. (2013), "Strategic Management under the Conditions of Uncertainty and Indefiniteness", Strategic Management, Vol. 18, No. 1, pp. 62-68.

10. Tan, X.C., Wang, Y.Y., Gu, B.H., Mu, Z.K., Yang, C. (2011), "Improved Methods for Production Manufacturing Processes in Environmentally Benign Manufacturing", Energies, Vol. 4, No. 9, pp. 1391-1409.

11. Vorhies, D.W., Morgan, N.A. (2005), "Benchmarking Marketing Capabilities for Sustainable Competitive Advantage", Journal of Marketing, Vol. 69, No. 1, pp. 80-94.

\section{About the authors}

Radovan Pejanović is Professor at the Faculty of Agriculture, Department of Agricultural Economics and Rural Sociology, University of Novi Sad. He obtained all titles from assistant to full professor. He teaches at the undergraduate, graduate and doctoral studies at Agricultural Economics studies and studies of Agro-tourism and Rural Development. He has published a number of papers (textbooks, monographs, scientific papers) and is associate (manager and coordinator) in several national and international projects. He is head of the Center for Rural Development, president of the Scientific Society of Agricultural Economists of Balkan and the president of the Editorial Board of the journal Economics of Agriculture as well as a member of the editorial board of the journal Annals of Scientific Work of the Faculty of Agriculture in Novi Sad and Contemporary Agriculture. He is the editor at the publishing house Academic Book from Novi Sad. Prof. Dr. Pejanović is certified accountant and auditor, assessor of capital, as well as an expert in economic and financial issues. The author can be contacted at pejanovic@uns.ac.rs. 
Otilija Sedlak is Professor at the University of Novi Sad, Faculty of Economics Subotica, working within the Department of Business Informatics and Quantitative Methods. She is involved in the realization of the teaching process on basic studies, master studies as well as on PhD studies in subjects close to her scientific interests. She is an author and co-author of several textbooks, scripts, notes and compendiums. Published or co-published over 30 scientific and professional papers in both national and international journals. She participated in the work on more than 80 scientific meetings that were published, either in whole or partly, in monographs or journals. The author can be contacted at otilijas@ef.uns.ac.rs.

Zoran Cirić is Professor at the University of Novi Sad, Faculty of Economics Subotica, working within the Department of Business Informatics and Quantitative Methods.

$\mathrm{He}$ is involved in the realization of the teaching process on basic studies, master studies as well as on PhD studies in subjects close to her scientific interests. He is an author and co-author of several textbooks, scripts, notes and compendiums. Published or co-published over 20 scientific and professional papers in both national and international journals. He participated in the work on more than 50 scientific conferences that were published, either in whole or partly, in monographs or journals. The author can be contacted at zoran.ciric@ef.uns.ac.rs.

Full Professor Leposava Grubić-Nešić, PhD, Department of Industrial Engineering and Management, Faculty of Technical Sciences, University of Novi Sad, Trg Dositeja Obradovica 6, 21000 Novi Sad, Serbia. Research interests: Human Resources Management, Leadership, Work Motivation, Work Psychology, etc. She is the author of the book Human Resources Management and of over 100 scientific research papers published in national and international journals and conferences Participates in several international and national projects; particularly engaged in cooperation with the industry. The author can be contacted at nesle@uns.ac.rs.

Assis. Prof. Slavica Mitrovic, PhD, Department of Industrial Engineering and Management, Faculty of Technical Sciences, University of Novi Sad, Trg Dositeja Obradovica 6, 21000 Novi Sad, Serbia. Research interests: production systems, organization and management, decision making, management principles in organization, entrepreneurship. She is the author of the book Principles of modern management and of over 70 scientific research papers published in national and international journals and conferences. Participates in several international and national projects; particularly engaged in cooperation with the industry. The author can be contacted at mslavica@uns.ac.rs.

Jelica Eremić-Đođić, PhD, is financial director of ODS (Distribution system operator "EPS Distribution"), EPS Distribucija, Masarikova 1-3, Beograd, Serbia. Research interests: distribution systems, financial management, business informatics, monitoring. She participates in several national projects; particularly engaged in cooperation with SAP. She is the author of about 20 scientific research papers published in national and international journals and conferences. The author can be contacted at jelica.eremic@ev.rs. 